\title{
Selecting optimal access for facial cyst removal: A case report and literature review
}

\author{
Marion Grob MRCSEng MRCSEd, Mark George Soldin FCSSA FCRSPlast
}

\begin{abstract}
M Grob, MG Soldin. Selecting optimal access for facial cyst removal: A case report and literature review. Can J Plast Surg $2005 ; 13(1): 31-32$.
\end{abstract}

Benign subcutaneous facial cysts are common in children and young adults. They are largely of cosmetic concern. Removal of sebaceous and epidermoid cysts in this population can leave unsightly scars, occasionally worse in appearance than the original pathology. In the present case report, the technique of cyst excision via an intaoral route is outlined. The literature review emphasizes the importance of placing facial incisions in inconspicuous areas.

Key Words: Concealed scar; Facial cyst

\section{Voie d'accès optimale pour l'exérèse d'un kyste facial : Rapport de cas et revue de la littérature}

Les kystes faciaux sous-cutanés bénins sont fréquents chez les enfants et les jeunes adultes. Ils sont la plupart du temps ennuyeux sur le plan esthétique. Et l'exérèse des kystes sébacés et épidermoïdes dans cette population peut laisser des cicatrices inesthétiques dont l'aspect est parfois pire que la pathologie au départ. Dans le présent rapport de cas, on décrit une technique d'ablation de kyste par voie intra-orale. La revue de la littérature souligne l'importance de choisir des sites discrets pour les incisions faciales.

\section{CASE PRESENTATION}

A 20-year-old healthy man presented with two adjacent subcutaneous cysts in his left cheek. They had been slowly enlarging over a number of years and each was now approximately $1 \mathrm{~cm}$ in diameter. Although the cheek appearance was normal in repose and when animated, the cysts were easily palpable bimanually. One behind the other, they resided $2 \mathrm{~cm}$ lateral to the commissure, and appeared equidistant from mucosal and skin surfaces clinically. There was no overlying skin punctum or skin distension.

Removal through a buccal mucosal approach under local anesthesia was straightforward. The incision was placed directly over the two cysts, anteroinferior to the parotid duct opening. The buccinator muscle fibres, and small branches of the facial nerve on the superficial aspect of the muscle, were parted during the dissection.

External pressure on the cysts was needed to deliver them into the mouth. Both cysts were attached to the skin and it was necessary to use sharp dissection to separate the superficial aspect of the cyst walls from the overlying dermis. Hemostasis and closure with an absorbable suture completed the procedure. Immediately after the operation, an obvious dimple was present on the external surface of the cheek, but this had resolved by six weeks (Figure 1). Although there were no signs of facial nerve weakness, the patient was aware of a scar within the mouth (Figure 2), but accepted this in preference to a cheek scar.

\section{DISCUSSION}

A number of different approaches to benign cyst excision from the face have been described. The commonly used route is via a cutaneous incision directly over the cyst. If the overlying skin is not attenuated or scarred from previous infection, a small stab into the cyst can be made, expressing the contents to allow the cyst wall to be teased out (1) and advantageously leaving a small skin scar. The risk of leaving behind some of the cyst wall and subsequent recurrence is, however, probably higher than with a larger incision. Therefore, to aid in cyst wall removal, the application of $5 \%$ phenol to the cyst cavity can assist in shrinking and toughening the wall (1). If, however, the phenol touches the skin surface, hypopigmentation can occur. Trephining of sebaceous cysts using a $4 \mathrm{~mm}$ skin biopsy punch followed by expression of the contents usually leaves a small pit which may require excision at a later stage (2). A similar marsupialization technique using a diathermy needle to cauterize a small area of skin and underlying cyst wall has been described as early as 1945 (3). In all the direct approach mini-incisions, it was thought necessary to excise the punctum of sebaceous cysts, and further variations on this theme exist (4).

Placing skin incisions in a cosmetically acceptable site, which may be well away from the lesion, allows the scar to be hidden. With this method, a greater dissection is often required to access the cyst, and skin punctum excision is not advocated (5). The authors suggested that the length of the incision should approximate the distance between the incision and the lesion, and used this approach in a variety of anatomical areas in a series of 28 patients. Experience with hiding incisions in the face allows plastic surgeons to be inventive if the individual case allows.

The blepharoplasty approach has been used by other authors (6) to remove dermoid cysts of the brow, and a rhytidectomy approach used to excise multiple cheek cysts (7). Only with an endoscope can lesions be removed via remote access, leaving behind small scars. Following the introduction of endoscopic brow lift techniques, surgeons have removed external angular dermoid cysts and other forehead lesions using these acquired skills (6). The risks to the temporal branch of the facial nerve, the length of operation and the 


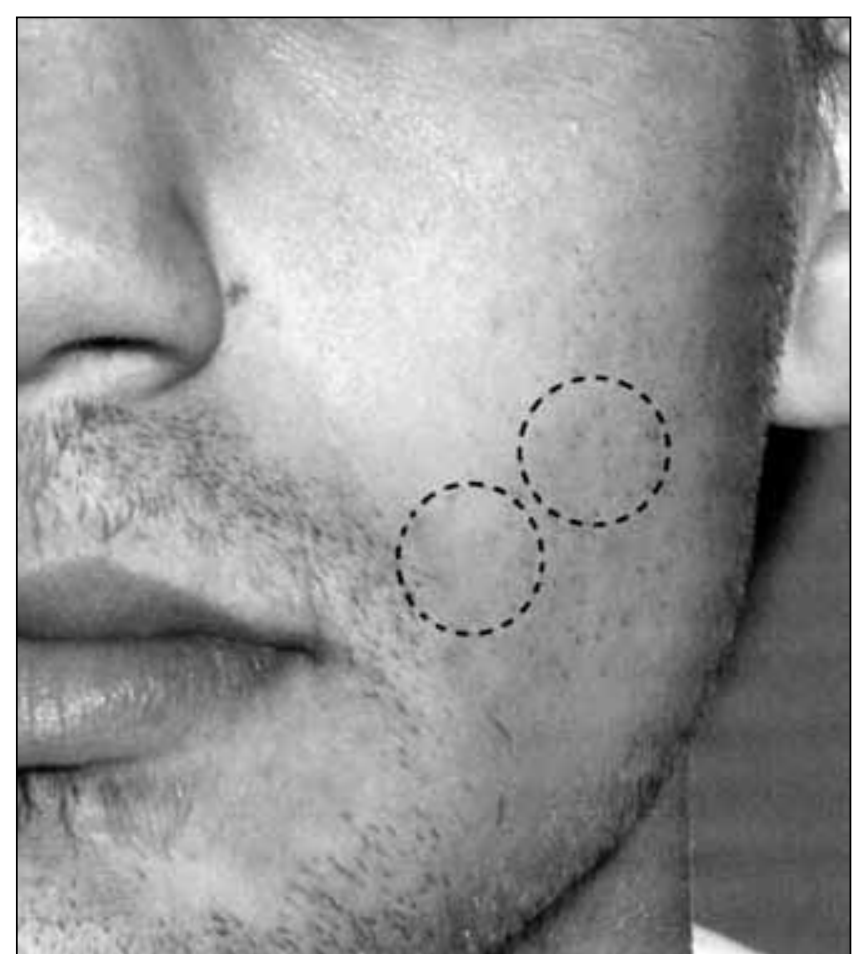

Figure 1) Left cheek six weeks after surgery. Dotted circles indicate preoperative cyst size and position

need for specialized equipment ensure continued controversy with this method. We have not seen it described for the removal of facial cysts.

Oral incisions are rarely used to excise cheek lesions, perhaps because operating in the confined space of the mouth is perceived as more difficult. Additionally, one is working from the deep surface up through the facial musculature and across the path of the facial nerve branches; however, the central face muscle function is forgiving with regard to local facial nerve damage. There is also a possible increased risk of infection because the oral mucosa is not a clean surface. Good facial vascularity, a small operation and adequate oral hygiene following surgery all help in diminishing infection risk.

The standard cutaneous incision directly over the cyst is still frequently required. The skin overlying the cyst is sometimes expanded or attenuated, and may need to be excised. Cyst recurrence following previous infection and drainage, or

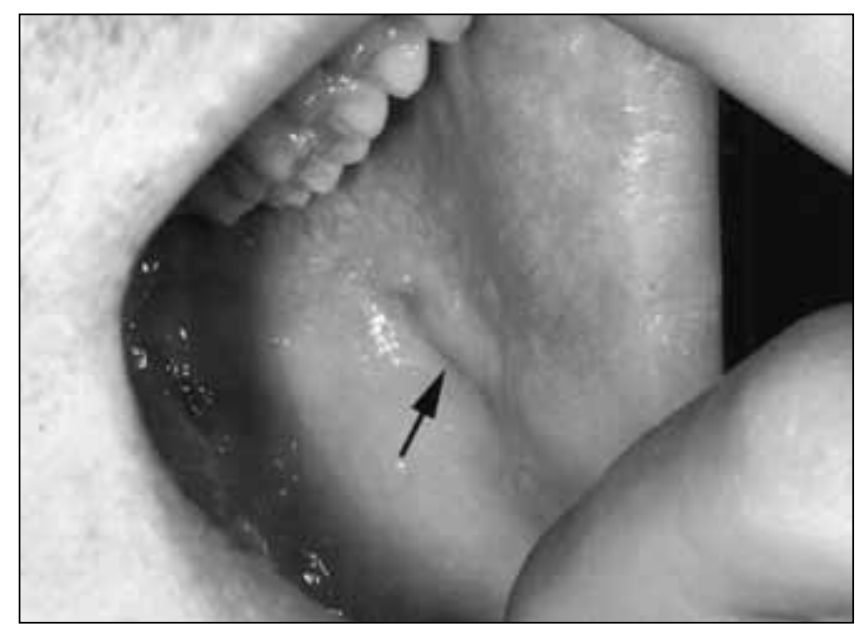

Figure 2) Intraoral view with arrow indicating prominent buccal scar below and anterior to the parotid duct opening

rupture, often requires excision with overlying scarred skin, ultimately leaving a longer, but neater, facial scar. The longer incision directly over the cyst is optimal in these circumstances and enables the cyst to be removed intact, and increases the certainty that the entire wall has been removed.

In removing these minor blemishes, it is easy to always opt for the most direct, quickest and simplest route, but the advantages of having a truly hidden scar in the face should not be overlooked.

\section{REFERENCES}

1. Moore C, Greer DM Jr. Sebaceous cyst extraction through miniincisions. Br J Plast Surg 1975;28:307-9.

2. O'Keeffe PJ. Trephining sebaceous cysts. Br J Plast Surg 1972;25:411-5

3. Dann JA. Simple treatment of sebaceous cysts. New Orleans Med Surg J 1945;98:5-8.

4. Vivakananthan C. Minimal incision for removing sebaceous cysts. Br J Plast Surg 1972;25:60-2.

5. Peinert RA, Courtiss EH. Excision from a distance: A technique for removal of benign subcutaneous lesions. Plast Reconstr Surg 1983;72:94-6.

6. Garrett WS, Ware JL, Thorne FL. Dermoid cysts of the brow, a technique of excision. Plast Reconstr Surg 1967;39:104-5.

7. Marshall KA, Kuhlmann TP, Horowitz JH, Silloway KA, Edlich RF Excision of multiple epidermal facial cysts in Gardner's syndrome. Am J Surg 1985;150:615-6. 